\title{
Investigations of Surface Urban Heat Island Effect Based on Local Climate Zone Method: A Case of Xi'an
}

\author{
Kaikai Mu ${ }^{1,2}$, Yan $\mathrm{Liu}^{1,2}$, Moyan Zhang ${ }^{1,2}$, Bing Han ${ }^{1,2}$, and Liu Yang ${ }^{1,2^{*}}$ \\ ${ }^{1}$ State Key Laboratory of Green Building in Western China, Xi' an 710055, P.R. China \\ ${ }^{2}$ School of Architecture, Xi' an University of Architecture and Technology, Xi' an 710055, P.R. China
}

\begin{abstract}
Urbanization seriously affects the urban climate and the quality of human settlement. Based on Landsat 8 remote sensing and building vector data, local climate zone (LCZ) method is employed to study the influences of urban form on land surface temperature (LST) of Xi'an. The results confirmed that the LST of the built-up LCZ is higher than the land cover LCZ. In built-up LCZ, LST is increasing with the increasing of building density. In land cover LCZ, the LST of bare land is the highest. Surface urban heat island (SUHI) of 14 samples in LCZ also been calculated. Highest SUHI intensity is found in low-rise buildings with high density area. LST intensity of water body and forest are lower than others in land cover LCZ.
\end{abstract}

\section{Introduction}

Rapid urbanization transformed land cover and urban form, also affects urban climate, led to series of climate problems such as urban heat island (UHI) effect [1]. UHI effect seriously affects the urban thermal environment and the quality of urban human settlement. Extreme heat caused by UHI effect can cause people illness even death [2]. UHI is also increasing the energy consumption of buildings cooling in summer, by 2020 , more than $35 \%$ of the total energy consumption is predicted to come from the building sector in China [3]. Aim to achieve the goal of energy saving and comfortable environment, strategies of alleviate UHI effect are urgently needed to explore. Therefore, studies on UHI effect have attracted many scholars, these studies usually take air temperature (AT) and land surface temperature (LST) as main indicators. The AT data were applied in that study of traditional UHI effect research. The LST data were used to study the surface heat island (SUHI) effect. These two indicators are mainly affected by underlying surface and urban form characteristics except solar radiation. Thus, studies were carried out around these factors.

Local climate zone (LCZ) method was proposed by Stewart [4] to distinguish urban land cover and urban form. This method has been used by many scholars to study SUHI effect. Researchers tested in different LCZ areas found that SUHI intensity was positively correlated with building surface fraction (BSF) and negatively correlated with ratio of green space (GSP) and water area fraction (WAF) [5-7]. AT data often have the defects of few stations and difficult to conduct research in large range. LST data inversed from the remote sensing image can represent the spatial distribution of urban thermal environment in a large scope. Therefore, remote sensing method has become an important method of SUHI research [8]. Researchers studied the influence of land cover and urban form characteristics on SUHI intensity. Found that SUHI intensity in the built-up area was significantly high, they also found that SUHI intensity is associated with high BSF $[9,10]$.

LCZ method comprehensively study the influence of land cover and urban form on SUHI effect. However, SUHI research based on this way in China is just beginning and mainly concentrated on coastal metropolis such as Shanghai [11] and Shenzhen [12], some inland cities were ignored. In this paper, building vector data and Landsat8 remote sensing image are used to classify LCZ in the main urban area of Xi'an firstly. Then LST was inversed from landsat8 data to calculate SUHI intensity. Finally, the influences of land cover and urban form on LST and SUHI intensity are obtained.

\section{Methods}

\subsection{Study area and data sources}

\subsubsection{Overview of Xi'an}

Xi'an is the capital of Shaanxi province. Located in the hinterland of Guanzhong Basin $\left(107^{\circ} 40^{\prime} \sim 109^{\circ} 49^{\prime}\right.$ East, $33^{\circ} 42^{\prime} \sim 34^{\circ} 45^{\prime}$ North), the mean altitude of the city area is approximately $400 \mathrm{~m}$ and the total land area about $10108 \mathrm{~km}^{2}$ [13]. The climate of Xi'an is influenced by temperate monsoon, with four distinctive seasons, January is the coldest and July is the hottest of the year. The prevailing wind direction is north-east [14]. The study area of this paper includes 6 districts in the main urban area about $936 \mathrm{~km}^{2}$. (Fig. 1)

\footnotetext{
* Corresponding author: yangliu@xauat.edu.cn
} 


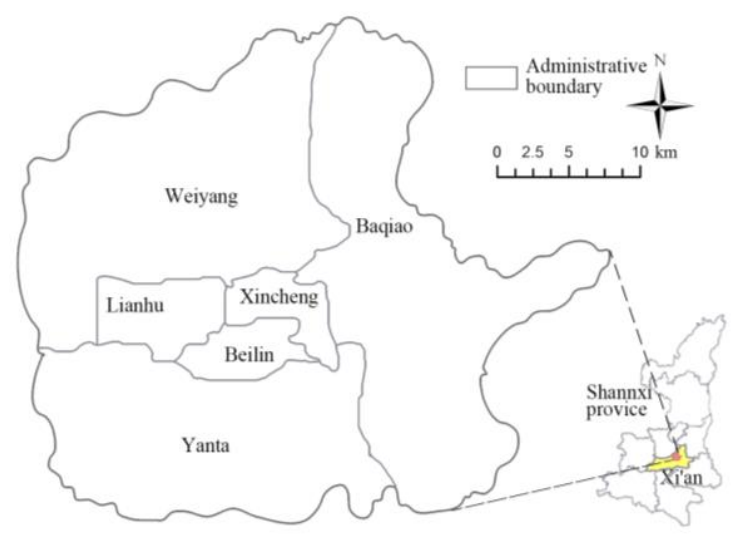

Fig. 1. Location of the study area.

\subsubsection{Data sources and pre-processing}

Landsat8 remote sensing image and building vector data of the main urban area of Xi'an are applied in this paper. Remote sensing image is used for land cover classification and LST inversion. The building data are used to calculate the urban form indicators. In order to improve the accuracy of data, Landsat 8 image is processed by merged, clipped, atmospheric corrected and radiometric calibrated in ENVI5.3 software. Building data are screened in Gis10.2 software. Table 1 is the data sources and descriptions.

Table 1. Data sources and descriptions.

\begin{tabular}{cccc}
\hline Data & Time & Source & Feature \\
\hline Building vector data & 2018 & Metrodatateam & The number of floors \\
Landsat8 remote sensing & $2016-6-17 ;$ & http://www.gsclou & Resolution: \\
image & $2017-4-17$ & d.cn/ & 30m (Multi-Spectral) \\
Map image & $2017-2019$ & Google Earth & 100m (Thermal) \\
& & one built-up LCZ types respectively. Table 2 shows \\
CZ classification & & building forms and corresponding built-up LCZ.
\end{tabular}

\subsection{LCZ classification}

Based on Landsat 8 remote sensing image and building vector data, this paper adopts UTM/WGS1984 projection coordinate system. Combine GIS and remote sensing classification methods to classify the LCZ of Xi'an. Divides into two categories, include land cover LCZ and built-up LCZ $[5,15]$.

\subsubsection{Built-up LCZ classification}

Gis 10.2 software is used to statistic the building data. The building height always divided into 5 categories: low-rise, multi-storey, middle-high rise, high rise and super high rise. Because the number of super high-rise buildings in Xi'an is less and scattered, the super high rise and high-rise buildings are combined and finally obtained 4 building height classifications.

Then, building density is calculated. Combined with the range of a LCZ area proposed by Stewart [4], $200 \mathrm{~m} \times 200 \mathrm{~m}$ grids are divided to calculate building density. Combine the height and density of buildings, 8 building forms can be obtained, these forms represented
Table 2. Building forms and corresponding LCZ.

\begin{tabular}{cl}
\hline LCZ type & \multicolumn{1}{c}{ Building Form } \\
\hline LCZ 1 & High-density high-rise building \\
LCZ 2 & High-density middle-high rise building \\
LCZ 3 & High-density multi-story building \\
LCZ 4 & High-density low-rise building \\
LCZ 5 & Low-density high-rise building \\
LCZ 6 & Low-density middle-high rise building \\
LCZ 7 & Low-density multi-story building \\
LCZ 8 & Low-density low-rise building \\
\hline
\end{tabular}

\subsubsection{Land cover LCZ classification}

The remote sensing image is conducted by supervised classification in ENVI 5.3 software. Classify land cover into grassland, farmland, forest, water body, bare land and impervious surface, represent one land cover LCZ type respectively. Table 3 shows all types of land cover and corresponding land cover LCZ. The imaging time of this remote sensing image is $11: 19$, April 17, 2017, the cloud cover is $0.18 \%$.

Table 3. Classification of underlying surface and corresponding LCZ.

\begin{tabular}{ccccccc}
\hline Land cover & Grassland & Farmland & Forest & Water body & Bare land & $\begin{array}{c}\text { Impervious } \\
\text { surface }\end{array}$ \\
\hline LCZ Type & LCZ A & LCZ B & LCZ C & LCZ D & LCZ E & LCZ F \\
\hline
\end{tabular}

\subsection{LST inversion}

Atmospheric correction method is used to retrieve LST through ENVI 5.3 software in this paper. The principle of this algorithm is as follows. Firstly, the surface thermal radiation intensity is obtained, it equal to the difference between the value of influence by atmosphere on surface thermal radiation and the total thermal radiation observed by satellite sensor. Then the thermal radiation intensity is converted into the corresponding 
LST. The imaging time of this remote sensing image is $11: 19$, June 17,2016 , the cloud cover is $0.03 \%$.

\section{Results}

\subsection{LCZ Classification}

Combine built-up LCZ and land cover LCZ to obtain 14 LCZ categories (Fig. 2). The results showed that there are few LCZ D in the main urban area, the built-up LCZ are mainly distributing in the middle, and the LCZ E is mostly distributing in the west and north. The vegetation LCZ in the built area is mostly LCZ A, the north of the built area is mostly LCZ A and LCZ B, the south is mostly LCZ B, and the LCZ C is mainly distributing in the east and southeast. The buildings of the main urban area are mainly low-rise and multi-storey. Baqiao district and Weiyang district are mostly low-rise and middlehigh buildings. Lianhu district and Xincheng district and Beilin district are mostly middle-high buildings due to these district are located in the area of keep historical city style. In general, the distribution of buildings in study area presents a trend of height gradually increasing and density decreasing from the central urban.

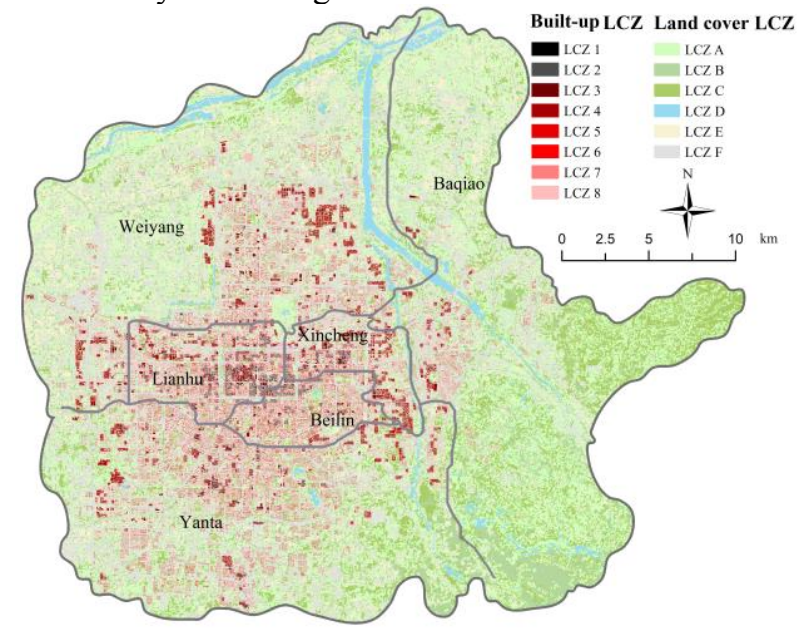

Fig. 2. Urban LCZ map of Xi'an.

\subsection{LST inversion results}

\subsubsection{Spatial distribution of LST}

The inversion result of LST is showed in Fig. 3. In general, the LST in the north is higher than south. The LST of built-up LCZ areas are higher than land cover LCZ areas. In land cover LCZ, the LST of LCZ E and $\mathrm{LCZ} F$ is significantly higher than others. Some areas of LCZ E in the north and southwest areas are extreme heat. The LST of LCZ D is the lowest.

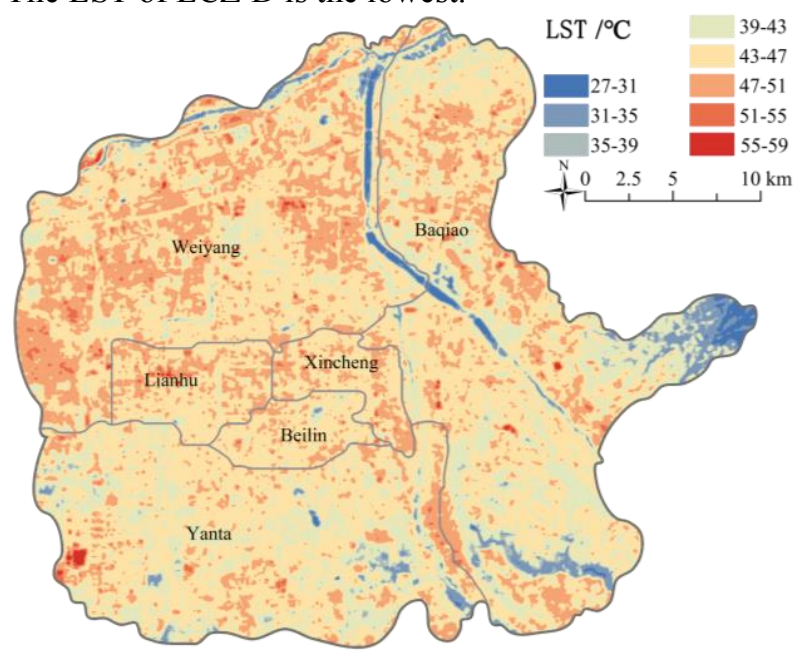

Fig. 3. LST distribution map of Xi'an.

The statistical results of LST showed that the temperature of land cover LCZ is generally lower than built-up $\operatorname{LCZ}\left(39.9^{\circ} \mathrm{C}<42.2^{\circ} \mathrm{C}\right)$. But the variation of LST in built-up LCZ area is more stable than land cover LCZ (Fig. 4). In built-up LCZ, the LST of high-density building areas are higher than low-density building areas. In land cover LCZ, the LST of LCZ E $\left(42.2^{\circ} \mathrm{C}\right)$ and LCZ $\mathrm{F}\left(41.4^{\circ} \mathrm{C}\right)$ are higher than others. Among three types of vegetation $\mathrm{LCZ}, \mathrm{LCZ} \mathrm{C}$ had the lowest temperature $\left(34.5^{\circ} \mathrm{C}\right)$ and the LCZB had the highest temperature $\left(42.2^{\circ} \mathrm{C}\right)$.

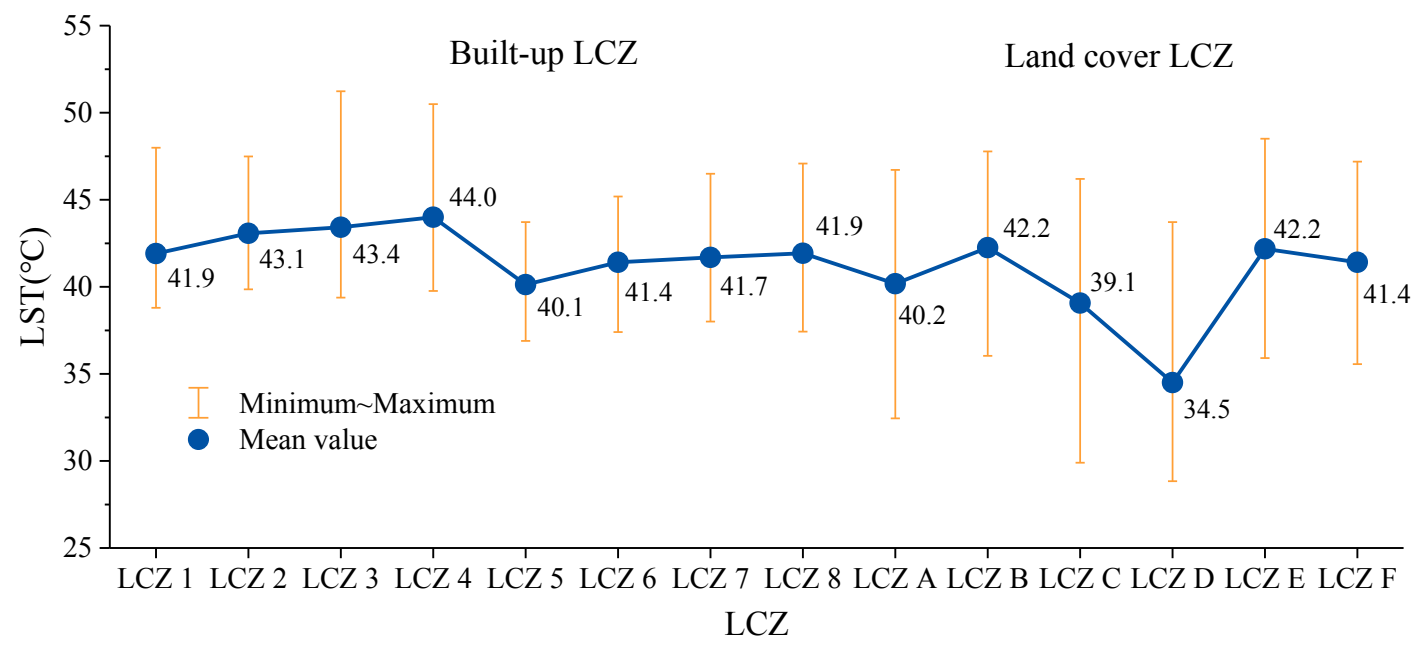

Fig. 4. Statistics of LST in different LCZ. 


\subsubsection{Sample analysis}

Statistical analysis shows that there are large range of LST variation in all LCZ types, in order to study the effects of LCZ urban forms on LST, 14 samples are selected from LCZ respectively for analysis. The diameter of each sample is 500 meters, then the LST of each sample are analysed. The urban form parameters of LCZ sample are calculated, adopted parameters include BSF, GSP and mean height of buildings (HRE). The samples' information are showed in table 4 . Moreover, a sample with diameter of $500 \mathrm{~m}$ is selected from the national reference climate station of Jinghe.

Table 4. Samples' information and urban form indicators of LCZ samples.

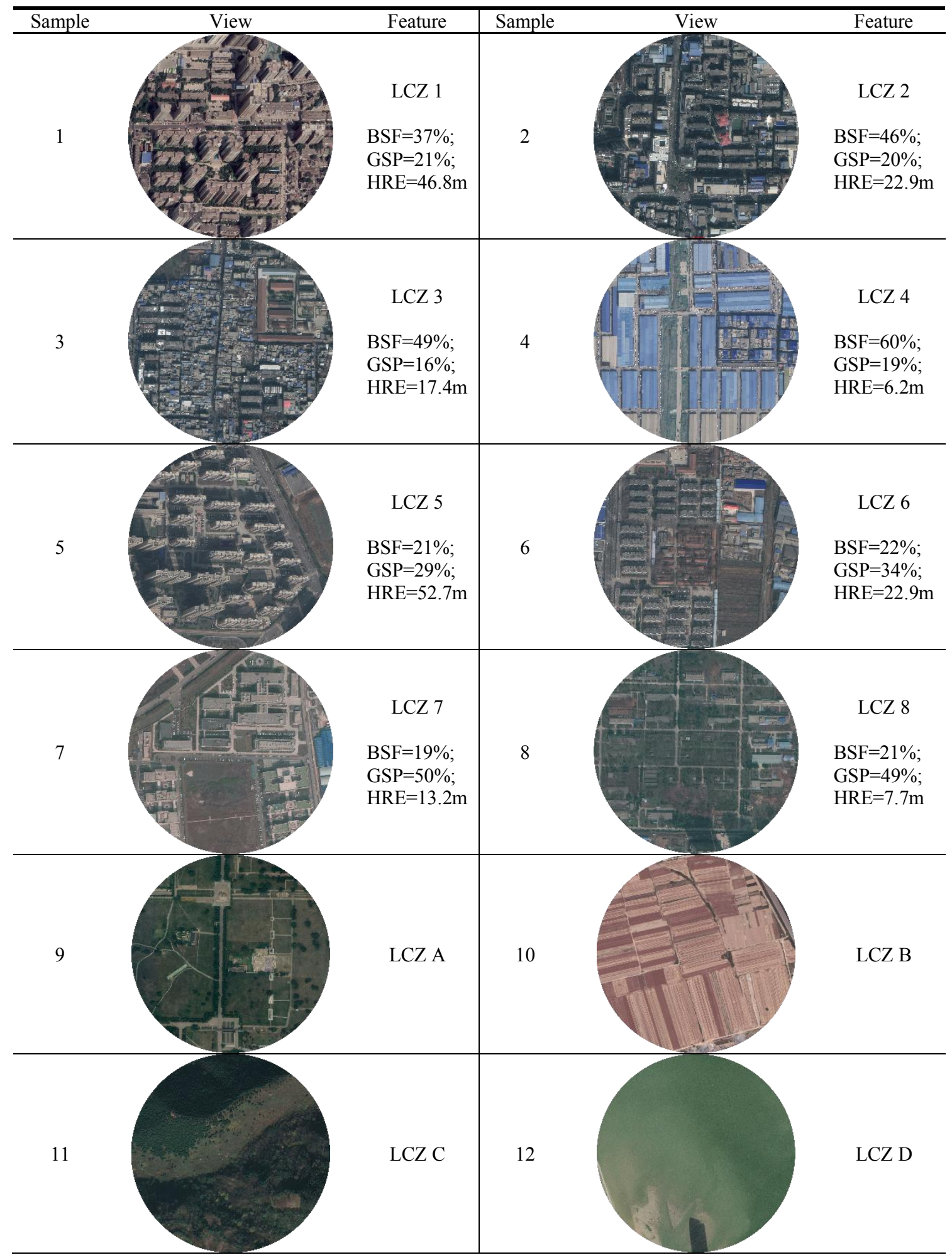


13

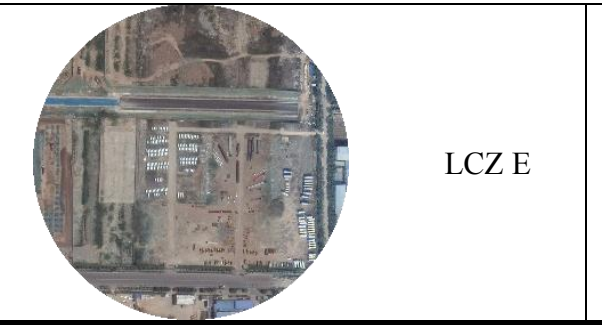

Statistical analysis result showed that the distribution trend of LST of each sample is roughly same as the corresponding LCZ. But the variation of LST of each

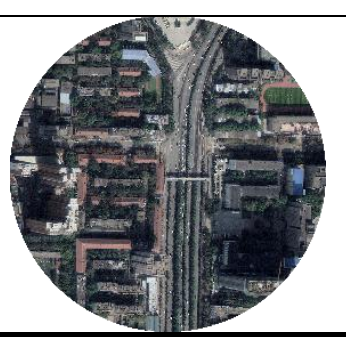

LCZ F

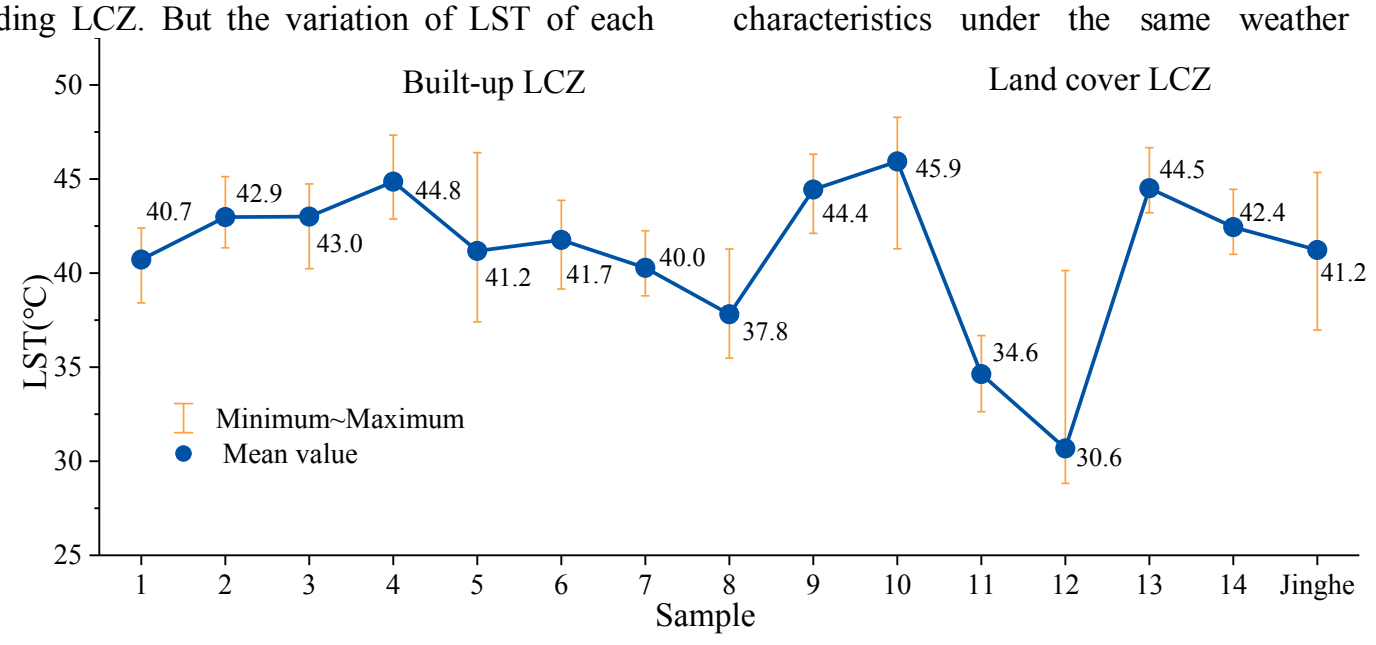

Fig. 5. Statistics of LST in different samples.

\section{Discussion}

UHI effect has become one of the most serious problems in urban climate. It is urgent to alleviate the UHI effect, which requires the combination of urban planning and urban climate. If city planners consider the impact of urban planning and design on climate, some problems can be avoided at the root. The research results of this paper confirmed that water body and greening can significantly alleviate the SUHI effect. Low-density high-rise buildings can conducive to shielding solar radiation and alleviate SUHI intensity. Thus, an attempt can be made to develop a high-rise and low-density building pattern. Add more vegetation and water body to improve urban thermal environment and provide more urban landscape.

LCZ as an objective method for urban climate research, has become the mainstream of relevant studies. However, there may have some problems in the classification process. For example, when using the classification method based on remote sensing, some cities will obtain the deviation of classification results due to the different distribution of plants under the influence of seasons, that should be noted in the classification process.

There are some limitations in this paper. For example, only the indicator of LST is applied to analyse the impact of LCZ on urban thermal environment. If meteorological data such as air temperature are added, a better effect may be obtained. In addition, some scholars pointed out that the urban thermal environment presents completely different conditions in different seasons and night $[16,17]$, the situation needs further study.

\section{Conclusions}

Taking Xi'an as an example, based on Landsat8 remote sensing image and buildings data, LCZ classification and LST inversion algorithm are employed in this paper. The influences of land cover and urban form on LST and SUHI intensity are obtained. The results showed that:

(1) In built-up LCZ, LST of high-density building areas are significantly higher than low-density areas due to the dense hard pavement and artificial heat release, as well as the reduction of ventilation and heat dissipation space. The shielding effect of tall buildings from solar radiation can reduce the LST. LCZ on bare land and impervious surface have higher temperature than others due to receive more solar radiation and strong heat storage capacity.

(2) LST is closely related to the architecture form and land cover, positively related with the BSF and negatively correlated with the GSP, water body and forest can relieve SUHI effect. Therefore, in urban planning and design, the density of buildings should be reduced, and the area of water body and forest land should be increased, these measures will play a great role in alleviating SUHI effect.

\section{Acknowledgement}

This work was supported by Natural Science Foundation of China (No. 51838011 and No. 51808429) and Young 
Elite Scientists Sponsorship Program by CAST, YESS (No. 2018QNRC001).

\section{References}

1. J. Liu, X. Lin, Y. Liu, Z. Sun. ACTA ENERGI SIN, 28, 912-917(2017).

2. D. Zhou, S. Zhao, L. Zhang, G Sun, Y. Liu. Sci Rep, (2015).

3. J. Liu, Y. Liu, L. Yang, T. Liu, C. Zhang, H. Dong. Renew Energy. 147, 356-373(2020).

4. I. D. Stewart, T. R. Oke. Bull. Am. Meteorol. Soc, 93, 1879-1900(12).

5. X. Yang, L. Yao, T. Jin, Z. Jiang, L. Peng, Y. Ye. J Civil, Archi Environ Eng, 41,160-167(2019)

6. D. Xu, D. Zhou, Y. Wang, W. Xu, Y. Yang. Build. Sci, 147(2019).

7. L. Liu, J. Liu, Y. Lin, D. Wang. Building. Sci, 33, 814(2017).

8. W. Wang, G. Zhang. GeSp. Info. Tec, 40, 194197(2017).

9. Y. Liu, J. Peng, Y. Wang. Remote Sens, 9, 919(2017).

10. J. Yang, J. Su, J. Xia, J. Cui, X. Li, Q. Ge. IEEE JSTARS, 11, 2709-2716(2018).

11. M. Cai, C. Ren, Y. Xu, K. K-L Lau, R. Wang, Urban. Cli, 24, 485-502(2018).

12. Y. Zhou. Study on the construction of urban heat island maps of Shenzhen based on local climate zone. HIT, (2016).

13. X. Feng. Remote sensing research on the evolution and origin of urban heat island. SNNU, (2012).

14. C. Ren, E Wu. Urban climatic map-an information tool for sustainable urban planning. (2012).

15. J. Yang, S. Jin, X. Xiao, C. Jin, J. Xia, X. Li, S. Wang. Sust. Cities Soc, 47(2019).

16. G. Zhao, J. Dong, J. Liu, J. Zhai, Y. Cui, T. He, X. Xiao. Remote Sens, 9,121(2017).

17. Y. Zhang, A. Murray, II B L Turner. Landsc. Urban Plan, 165,162-171(2017). 